\title{
The Physically Impaired Children in Rural South Africa: The Assessment of their Psychosocial Challenges
}

T.Mucharunga

T. Pitso

Department of Psychology, University of Fort Hare, Private Bag X1314, Alice, 5700

Email:200909578@ufh.ac.za/tsoloz2002@yahoo.co.uk

\section{Doi:10.5901/mjss.2014.v5n23p2285}

\section{Abstract}

The qualitative study investigated the psychosocial challenges which the physically impaired children are experiencing in their society. Open-ended questionnaire was used to conduct the in-depth interviews which were meant to be friendly for both literate and illiterate impaired children. The following ethics of conduct were put into cognizance: - The permission from the guardians, the school principals and respondents was granted. - Informed consent was granted from the respondents.Confidentiality, anonymity, voluntary participation and withdrawal from the study were guaranteed from 30 respondents. Qualitative thematic analysis was employed. The analysis helped the researchers move their analysis from a broad reading of the data towards discovering patterns and developing themes. The study came up with the findings that the physically impaired children face challenges such as isolationism, neglect, lack of basic and extra-mural facilities.

Keywords: Physically impaired, Psychosocial, Challenges

\section{The Physically Impaired Children}

Children are the custodians of the future of any community, society or country therefore their rights and needs have to be secured and served. The provision of these needs have, however, become a challenge facing many developing countries and the plight for disabled children is even worse. In South Africa, a prevalence rate of $3 \%$ has been noted meaning that 155000 children from birth to four years have a moderate to severe disability (UNICEF\& The Presidency, 2009).In 2009, using the WG Short Set of Questions to measure disability, the general household survey classified 2,1 million children, who constitute $11,2 \%$ of the total child population as disabled (UNICEF, Department of Social Development \& Department of Women, Children and People with disabilities, 2012).

Some rural areas lack of facilities conducive for disabled children because they are already marginalised and underdeveloped leaving a number of impaired children isolated. In South Africa, people with physical deformities have been excluded from society and face huge challenges accessing their political, economic and social rights (Office of the Presidency, 1997). The introduction of inclusive learning, which is a process of addressing the diverse needs of all learners by reducing barriers to, and within the learning environment (Walton, 2009) shows that physically challenged children, had been overlooked for long. An estimated 165000 children were out of school in 2011 (Mashaba, 2012). Eighty per cent of black children with disabilities live in extreme poverty with limited access to health care and early childhood development facilities (Office of the Presidency, 1997). Most rural areas are occupied by the black population and these are the areas which are usually underdeveloped and marginalised.

According to the South African Human Rights Commission (2012), in 2009, 97\% of public schools in South Africa are not conducive for children with disabilities as they do not have the structures and facilities which can be used by physically challenged children. The Department of Social Development survey reported that of the 13000 children living in registered child and youth care centres, $28 \%$ of them were found to have one kind of disability yet many centres lack the capacity to cater for disabled children (UNICEF, Department of Social Development \& Department of Women, Children and People with disabilities, 2012). Another major challenge has been defining disability. There are no clear uniform definitions and these impinge identification, diagnosis, record keeping and statistics (Child Health Policy Institute, 2001). This then implies that there are reliability concerns when it comes to information pertaining to disabled children in South Africa. It is against such a background of marginalisation and exclusion that this study was conducted. 


\section{The Psychosocial Experiences of Physically Impaired Children}

In addition to the general challenges that are faced by the physically challenged children in South Africa, children in rural areas are often confronted with a different set of challenges due to marginalisation of the areas they stay, illiteracy of the majority of the inhabitants of their of the area, a lack of facilities, support structures as well as a lack of information on disability. Inaccessibility to information also expose physically deformed rural children to a different set of challenges as compared to their urban counterparts who live in more accepting environments with better informed people and where support structures exist. Some of the psychosocial experiences of the physically impaired children noted in rural areas included:

\subsection{Neglect}

The study showed that some parents or guardians did not regularly visit their physically challenged children and class teachers to discuss and track their academic and social progress. While the teachers felt that parents did not visit their children because they did not want to identify with them, on the contrary, most parents indicated not visiting their children due to fear of being labelled by the community members. This shows that these children were being neglected by their parents and guardians whilst warmth and parental involvement are among factors which determine the effectiveness of parents as socialisation agents (Louw, Van Ede \& Louw, 1998). In an environment which does not have any strong supporting structures for the disabled children, this neglect affected their self-esteem and the way they viewed their physical impairment. Whilst efforts by the school helped the children feel better about themselves, little could be achieved without the support and care of parents and guardians. Families play a central role in the building of children's selfesteem and trust more so when they have a challenge like a physical impairment. Neglect also extends to interfere with their ability to interact with their peers, leading to isolation. Social interaction facilitates cognitive and social developments which are critical to formation of a better adult personality. Children with well nurtured social and emotional skills are healthier, focused and less impulsive and have improved relationships with others and academic achievement (Palomares, 2010).

\subsection{Lack of disabled-friendly facilities}

This study identified an acute lack of special facilities and support services to enhance the environment where the physically challenged children live or learn. The lacking services ranged from specialist teachers in physical challenges, shortages of learning materials, lack of ramps for easy access to classrooms, and lack of adequate adapted toilets and cemented pavements in most schools. As a result, most of the homes for the physically challenged children and the school lack the capacity to effectively integrate these children. In Alice there are also no appropriate facilities like playgrounds which can enable the physically challenged children to play without any harm and which would make them feel like part of the community. In such environments, children can become victims of play disruption which is an inability to play because the child's emotions are preventing the kind of free expression linked with the fun of play(Scarlett, Naudeau, Salonius-Pasternak,\& Ponte,2005). The few recreational facilities available are not accommodative to children with physical defects leading to further isolation. The non-availability of these structures denies them an opportunity to interact and play with other children and ultimately affects the development of their social, cognitive and motor skills.

\subsection{Isolation}

According to the findings of the study, the physically challenged children who participated in the study ranged from seven to eighteen years both male and female. These children acknowledged isolation as a challenge they are facing. In the findings the researchers noted that these children are mainly isolated by their peers in the community and other adults in their community. The researchers thus noted that Alice community lacks knowledge on how to interact with children who are physically challenged. According to the study, the forms of isolation in Alice community which the physically challenged children face range from mockery, labelling and rejection which lead the physically challenged children to shy away from other children. This affected their emotional development since friendships contribute to emotional development by giving children an opportunity to experience intense emotional bonds with other people other than their caregivers (Baron \& Kalsher, 2008). The study showed that some parents of the physically challenged children did not allow their children to go out and play with others because they were afraid that their children will be mocked and abused by other children. The bodily deformed children are isolated in a variety of ways and by different sectors of society. Most 
societies do not seem to pay attention to their special needs and they remain an ignored section of the society.

\subsection{Emotional problems}

Emotional problems were also reported by the children as a result of the isolation they faced. Most of them reported feeling frustrated, pain, depressed and angry. According to Thompson (2003) children with physical challenges are often frustrated, and that leads to anger. They see the other children playing and they want to participate. A lack of proper support structures denied them channels to deal with the social rejection they faced. The researchers also noted that the physically impaired children were not regarded as human beings with other abilities other than the physical ones. They were looked down upon and were not given the space to express their views, feelings or opinions in general conversations with other children without impairments. Society's lack of information regarding issues of disability has resulted in prejudice which made these children victims of discrimination and stigmatisation. In some cases physically challenged children have been labelled as aggressive which could be a result of their frustration towards themselves for being disabled and society's continuous lack of regard for their welfare and needs. When these children caught in this situation, without any supporting structures, they are left without any space to process their grief or deal with it in other healthy, socially acceptable ways. They then develop a behaviour which further alienates them other children and from society in general thereby building more frustration. Therefore, the lack of opportunities for them to process their frustrations result in them being trapped in a cycle of isolation, anger, frustration and emotional instability. In cases where even the family members show little concern for their welfare, their situation escalates.

\subsection{Lack of information/knowledge}

The study also found that the community lack knowledge with regards to the needs of physically impaired children. Most physically challenged children, despite being well treated at home and sometimes by peers, the broader community subject them to stigma. The community is ignorant to the plight of physically challenged and do not understand how pivotal its role is in ensuring the integration of physically challenged children. Acceptance, accommodation and avoiding stigmatizing the physically challenged children can greatly reduce their isolation. Mittan (2012) concurs by stating that, "Stigma is a common problem among the physically challenged community. Often society is not very accepting of illness and disability and the person affected becomes stigmatized as a result. The person is shunned. Social opportunities are denied. Self-esteem suffers."

\section{Psychosocial Theory of Erikson and Piaget's Cognitive Development Theory}

Piaget and Erikson's theories form the basis of human development starting from the infancy stage to late adulthood. Erikson believed that personalities are shaped by how well people deal with the psychosocial crises encountered at each stage and Piaget suggested that children at different stages differ in their view and interaction with the world (Nevid, 2012). The study focused on the infancy to late childhood. For purposes of this study the first three stages of Piaget's theory and the first four stages of Erik Erikson's theory will be explored.

According to Papalia, Olds and Feldman (2009), Erikson's first stage of psychosocial development is characterised by trust vs mistrust of which if the stage is well completed, hope will be the result. Failing-which, withdrawal will emerge. In the sense of the rural society, the physically impaired children are often associated with superstitious beliefs such as witchcraft, curse, or even neighbours and relatives being scapegoats. These elements of superstition are rooted in cultural traits such as education and belief. In essence, Piaget's sensorimotor stage of cognitive development will be influenced by such environments (Gustafsson and Worku 2007). Once the children are born in an environment where their physical condition is believed to be a result of such factors such as witchcraft, the treatment they are given will be different compared to the one given to other children without any physical deformities. This treatment has the potential to even affect their ability to explore their environment hence impact on the development of their sensory and motor skills and ultimately their mastery of the sensorimotor stage.

The autonomy vs shame crisis characterises Erikson's second stage in which will is achieved when this stage is handled properly whilst compulsions manifest when mishandled (Papalia et la, 2009). Most physically challenged children, however, are prone to develop shame leading to compulsions as most parents and guardians are usually too protective of them, denying them opportunities to freely express themselves, therefore their sense of autonomy is mostly not fully realised. This stage also coincides with Piaget's pre-operational stage which is characterised by symbolic thinking, imagination and egocentric thinking among others. In some instances, some children are mentally handicapped 
which shutters their cognitive development process and with the non-existence of skilled helpers, institutions and facilities as is the case in most rural areas, most these children are denied the mental stimulation they need and crumble, cognitively.

Initiative vs guilt forms the third crisis in Erikson's theory which is experienced by children between the ages of 35.In this crisis, children who are allowed to initiate develop a sense of initiative and those who are not given this freedom develop guilt. The study found that physically impaired children are neglected, and in rural areas they even lack supporting tools, items and gadgets to facilitate their movement and help them explore and stimulate the development of a sense of initiative. The aiding devices help some of the children, for instance, those whose disabilities have rendered them immobile. Disabled children who have access to these aiding devices have a better chance of taking initiatives than those who do not which leaves most handicapped rural children at a disadvantage. This crisis is also covered by the preoperational stage of Piaget which was discussed earlier.

Piaget's concrete operational stage is characterised by the application of logic, conservation and rational interpretations, which is construed as the industry vs inferiority crisis in Erik Erikson's theory of psychosocial development. Children who are physically impaired but not mentally challenged have the ability master concepts such as conservation, apply logic and meaningful interpretations. Those who were mentally challenged, however, had difficulty in making meaningful interpretations and applying logic during the course of the study. Due to the labelling, social exclusion, most physically handicapped children had developed a sense of inferiority at the expense of their industrious potential.

\section{Conclusion}

Children who are physically impaired tend to struggle in exploring their environment due to their parents and guardians being overprotective of them, or lacking the proper tools to help them move around. Handicapped children in rural areas are side-lined in as far as the provision of their special needs is concerned. The inclusive education approach adopted by the South African government still falls short in implementation in rural areas as disabled children are still being institutionalised and denied integration into mainstream education. Most schools do not have the conducive facilities to accommodate physically impaired children which inhibit the children from acquiring the education they need hence are not able to live up to their full potential. Physical impairment in the rural areas has also proved to affect the psychosocial and cognitive development of children and denies the widely held acclaim that "Disability does not mean inability". Efforts towards serving the needs of the physically impaired children in rural areas have thus remained largely inadequate.

\section{Recommendations}

- Civil society, non-governmental organisations, public and private sectors should lobby for better treatment and the welfare of physically challenged children.

- More research should be done on physically impaired children in rural areas as they remain an abandoned, excluded and isolated group of society.

- The government should have a relook on the implementation of the inclusive education approach in rural areas where schools are either lacking facilities conducive for physically impaired children or non-existent altogether.

- Community awareness programmes need to be carried out to sensitise and educate communities on issues regarding physical impairment.

- Campaign rallies should also be carried out, directed at ending the abuse and violence against physically challenged children.

- The government should prioritise the integration of physically challenged children into the mainstream education sector.

- Specialist services providing services such as trauma counselling need to be made accessible to handicapped children in rural areas.

\section{References}

Baron, R.A \& Kalsher, M.J. (2008). Psychology: From Science to Practice.2 $2^{\text {nd }}$ Ed. United States of America: Pearson Education Inc.

Child Health Policy Institute. (2001).Summary of literature: Disability and Chronic illness prevalence in children in South Africa. Rondebosch

Department of Social Development, Department of Women, Children and People with disabilities \& UNICEF. (2012).Children with 
Disabilities in South Africa: A situation analysis: 2001-2011.Pretoria: Department of Social Development/Department of Women, Children and People with disabilities/UNICEF

Louw, D.A., Van Ede, D.M. \& Louw, A.E. (1998).Human Development.2nd Ed. Cape Town: Kagiso Tertiary

Mashaba, S. (2012). The Sowetan: Little hope for children with disabilities. Downloaded from http://www.sowetanlive.co.za/news/2012/ 01/05/little-hope-for-children-with-disabilities

Mittan, J., (2012). Understanding and coping with stigma of disabilities. Retrieved October 20, 2012, from http://www.webmd.com.

Nevid, J.S. (2012).Essentials of psychology: Concepts and applications.3rd Ed. Wadsworth: Cengage Learning

Office of the Presidency. (1997). Integrated National Disability Strategy-White Paper. Downloaded on 15 July, 2014 from http://www. independentliving.org/docs5/SANatlDisStrat.htm|\#anchor1

Palomares, S. (2010). Social-Emotional learning activities for After-school and Summer Programs. Wellington: Innerchoice Publishing

Patton, M.Q. (2002). Qualitative evaluation and research methods. (3rd Ed). California: Sage Publications Inc.

Scarlett, W.G., Naudeau, S., Salonius-Pasternak, D., \& Ponte, I. (2005).Children's play. Thousand Oaks, CA: Sage

South African Human Rights Commission. (2012).Charter of Children's Basic Education Rights: the right of children to basic education. Downloaded on 16 July, 2014 from http://www.sahrc.org.za

The Presidency \& UNICEF. (2009). Situation analysis of children in South Africa. Downloaded on 15 July, 2014 from http://www.thepresidency.gov.za/docs/pcsa/gdch/situation-analysis.pdf

Thompson, E. (2003). Raising a handicapped child: A helpful guide for parents of the physically handicapped children. USA: Oxford University Press.

Walton, E.L. (2009). Inclusive Education South Africa. Downloaded on 15 July, 2014 from

http://www.inclusion.co.za/pages/contact.us.php 